\title{
MORFOLOGIA DE FRUTOS E SEMENTES DE ESPÉCIES ARBÓREAS DO GÊNERO Solanum L. ${ }^{1}$
}

\author{
ESTELA DALPIM CASTELLANI², CARLOS FERREIRA DAMIÃO FILHO ${ }^{3}$, IVOR BERGEMANN DE AGUIAR ${ }^{4}$, \\ RINALDO CÉSAR DE PAULA ${ }^{5}$
}

\begin{abstract}
RESUMO - O objetivo do trabalho foi caracterizar a morfologia do fruto e da semente de três espécies florestais nativas do Brasil, Solanum granuloso-leprosum Dunal, S. lycocarpum A.St.Hil. e S. pseudoquina A.St.-Hil., recomendadas para plantações destinadas à recuperação de áreas degradadas. Os frutos são indeiscentes, carnosos, do tipo baga, globosos, polispérmicos e constituídos por dois ou mais lóculos. As sementes são estenospérmicas, campilótropas, elipsóides, comprimidas, apresentando seção longitudinal largo-ovalada ou achatado-ovalada e seção transversal elíptica. Hilo mediano-marginal localizado em uma depressão e micrópila arredondada. Sementes albuminosas, com endosperma abundante, periférico, carnoso-firme, semitransparente e de coloração esbranquiçada. Embrião axial, linear, contínuo e curvado. Em Solanum lycocarpum e S. pseudoquina o embrião é circinado e em S. granuloso-leprosum é espiralado.
\end{abstract}

Termos para indexação: Solanum granuloso-leprosum, S. lycocarpum, S. pseudoquina, sementes florestais.

\section{FRUIT AND SEED MORPHOLOGY OF SOLANUM L FOREST SPECIES}

\begin{abstract}
The aim of this study was to characterize the fruit and seed morphology of three Brazilian forest species, Solanum granuloso-leprosum Dunal, S. lycocarpum A.St.-Hil. and S. pseudoquina A.St.-Hil., recommended for plantations of degraded area recovery. The fruits are indehiscent, fleshy, berry type, globouse, polispermic and consist of two or more loculus. The seeds are stenospermics, campylotropous, elliptics, compressed, presenting broad-ovate or flattened-ovate longitudinal section and elliptical transversal section. Hilum medioum-marginal situated in a depression; rounded micropyle. Seeds albuminous, with abundant endosperm, peripherical, fleshy-firm, semitransparent and of white coloration. Axile, linear, continuous and curved embryo. Solanum lycocarpum and $S$. pseudoquina present circinate embryo and S. granuloso-leprosum spirally embryo.
\end{abstract}

Index terms: Solanum granuloso-leprosum, S. lycocarpum, S. pseudoquina, forest seeds.

\section{INTRODUÇÃO}

Estudos da morfologia externa e interna das unidades de dispersão são importantes para a identificação das plantas

${ }^{1}$ Aceito para publicação em 24/11/2007; parte da Tese de Doutorado da primeira autora apresentada à FCAV/UNESP, financiada pela FAPESP

${ }^{2}$ Biólogo, Fundao Nacional do Meio Ambiente, Ministério do Meio Ambiente, e-mail: estela.castellani@mma.gov.br (autor para correspondência)

${ }^{3}$ Eng $^{\circ}$ Agrônomo, Prof. Depto. Biologia Aplicada à Agropecuária, FCAV/ UNESP, CEP 14870-000, Jaboticabal - SP, e-mail: damiao@fcav.unesp.br das quais estas foram originadas. A morfologia de frutos e sementes, muitas vezes, fornece informações sobre o estágio de maturação das sementes, possibilitando a definição da época de colheita. Segundo Piña-Rodrigues e Aguiar

${ }^{4}$ Eng $^{\circ}$ Agrônomo, Bolsista do CNPq, Prof. Titular Voluntário do Depto. de Produção Vegetal da FCAV/UNESP, CEP 14870-000, Jaboticabal -SP, e-mail.ivor@netsite.com.br

${ }^{5}$ Eng $^{\circ}$ Florestal, Prof. Depto. Produção Vegetal da FCAV/UNESP, CEP 14870-000, Jaboticabal - SP, e-mail: rcpaula@fcav.unesp.br 
(1993), a maturidade fisiológica geralmente é acompanhada por modificações visíveis no aspecto externo dos frutos e sementes, tais como a coloração, a textura, a forma, o tamanho e o peso, entre outros.

A diversidade morfológica de frutos e sementes constitui adaptações para a dispersão dessas estruturas, por diferentes meios (Van Der Pij1, 1982). Segundo Pinheiro e Ribeiro (2001), a morfologia de frutos e sementes é útil como ferramenta para a caracterização das síndromes de dispersão das espécies.

O planejamento do tipo de processamento a ser adotado para as sementes também depende do conhecimento prévio sobre a morfologia de frutos e sementes. Silva et al. (1993) e Silva (1995) relataram que o método de secagem e extração de sementes de espécies florestais depende das características morfológicas dos frutos, bem como de sua consistência e deiscência. Segundo esses autores, o beneficiamento das sementes só pode ser adequadamente realizado, quando se tem conhecimento prévio da morfologia desses órgãos.

A caracterização morfológica das sementes permite a obtenção de informações sobre a germinação, bem como a identificação de dormência, como a ocasionada por tegumento impermeável, que impossibilita a entrada de água e gases, ou mesmo a dormência causada por imaturidade do embrião.

Segundo Groth e Liberal (1988), os trabalhos de morfologia de sementes auxiliam ornitólogos, que trabalham com aves consumidoras de sementes, pois fornecem dados sobre a rotina migratória ou sobre o hábito alimentar das mesmas. Esses conhecimentos podem, também, ser aplicados no manejo e na conservação da fauna silvestre, bem como em estudos de dieta de herbívoros (Kuniyoshi, 1983).

A morfologia de frutos e sementes está diretamente relacionada com a regeneração natural, determinando o comportamento das espécies durante a dispersão, a formação do banco de sementes e de plântulas, a própria germinação e a longevidade (Kageyama e Viana, 1991).

Os trabalhos com a morfologia de sementes e de plântulas são também importantes por subsidiarem pesquisas sobre banco de sementes do solo e chuvas de sementes provenientes de árvores e de agentes dispersores. São importantes, ainda, para auxiliar a identificação das espécies em estudos de regeneração natural de áreas degradadas.

Apesar dos trabalhos de morfologia servirem de base para vários outros estudos, estes são raros para a maioria das espécies florestais brasileiras. Especificamente para espécies de Solanum são escassas as publicações que contemplam a descrição de sementes e frutos, com exceção dos trabalhos de Kissmann e Groth, (1995) e Kissmann e Groth (2000). Inexistempublicaçõesque focalizam diferenças interespecíficas de sementes e frutos de Solanum e, em tal aspecto, destacam- se Solanum granuloso-leprosum Dunal., S. lycocarpum A.St.Hil. e S. pseudoquina A.St.-Hil., objetos do presente trabalho, as quais são recomendadas por Davide et al. (1995), Trape e Oliveira (1995), Prado et al. (1996), Prado et al. (1999) e Castellani (2003) para a recuperação de áreas degradadas.

S. granuloso-leprosum é conhecida popularmente por gravitinga, capoeira-branca, fumo-bravo, entre outros nomes, sendo encontrada nas regiões sudeste e sul do Brasil, Paraguai, Uruguai e Argentina (Roe, 1972).

S. lycocarpum é conhecida popularmente por lobeira, fruta-do-lobo e jurubebão, ocorrendo naturalmente em todo o Brasil tropical e subtropical, com predominância nos cerradões, cerrados e campos cerrados (Almeida et al., 1998; Lorenzi, 1998).

S. pseudoquina, vulgarmente chamada de quina-desão-paulo ou joá, é típica de mata semidecídua de altitude, ocorrendo nos Estados de Minas Gerais, São Paulo e Paraná em mata latifoliada semidecídua de altitude (Lorenzi, 1998).

Em vista do que foi exposto, o presente trabalho teve por objetivo caracterizar morfologicamente os frutos e sementes das três espécies de Solanum citadas.

\section{MATERIAL E MÉTODOS}

Os frutos e as sementes das solanáceas estudadas foram coletados ao longo do ano de 2000 nos municípios de Caconde, Cajurú, Guatapará, Iracemápolis, Jaboticabal, Ribeirão Preto, Santa Rosa do Viterbo e Santo Antônio da Alegria, no estado de São Paulo, e nos municípios de Delfinópolis e Nepomuceno, em Minas Gerais. Em seguida, eles foram transportados para o Departamento de Produção Vegetal e de Biologia Aplicada a Agropecuária da Universidade Estadual Paulista, em Jaboticabal, onde foram analisados.

O tamanho dos frutos foi representado pelo diâmetro, mensurado com o auxílio de paquímetro eletrônico, utilizando-se cinco repetições de 10 frutos coletados ao acaso de cada espécie.

O tamanho das sementes foi mensurado utilizando-se 10 repetições de 10 sementes para cada uma das espécies estudadas; foram feitas medições do comprimento, da largura e da espessura das sementes. Para Solanum granuloso-leprosum, cujas sementes são muito pequenas, as medições foram feitas através de gratícula com escala micrométrica acoplada a ocular do estereomicroscópio. Para S. lycocarpum e S. pseudoquina, cujas sementes são maiores, as medições foram feitas com paquímetro eletrônico. Foi elaborado o gráfico de distribuição da freqüência das médias tomadas em cada semente, por categoria de comprimento, largura e espessura.

Para a descrição morfológica, as sementes foram previamente embebidas em água destilada por 12 
horas, cortadas com lâmina de barbear e observadas em estereomicroscópio, sendo fotografadas e posteriormente descritas. Algumas amostras de sementes foram observadas em microscópio eletrônico de varredura. Após 12 horas embebidas em água, foram cortadas ou deixadas intactas, sendo preparadas para observação conforme prescrições de Santos (1992). A descrição morfológica foi feita com base em Corner (1976), Groth e Liberal (1988), Damião-Filho (1993) e Barroso et al. (1999).

\section{RESULTADOS E DISCUSSÃO}

Morfologia dos frutos. Os frutos das espécies estudadas de Solanum são indeiscentes, carnosos, do tipo baga, globosos e polispérmicos. Barroso et al. (1999) se referem aos frutos das espécies de Solanum como bacóides do tipo solanídios. Os frutos são constituídos por dois ou mais lóculos, com a cavidade central repleta de polpa carnosa. Foram observados cálices gamossépalos, com cinco lobos na extremidade, persistentes nos frutos maduros.

S. granuloso-leprosum apresenta frutos com 0,50 a $1,89 \mathrm{~cm}$ de diâmetro, com epicarpo verde mesmo quando maduro e tomentoso. Mesocarpo e endocarpo são constituídos por polpa branco-amarela (Figuras 1A a 1C).

Os frutos de S. lycocarpum (Figuras 1D a 1F) apresentam de 7-16cm de diâmetro, com endocarpo verde mesmo após o amadurecimento, tomentoso e com pequenos pelos que se desprendem quando tocados. Meso-endocarpo constituído
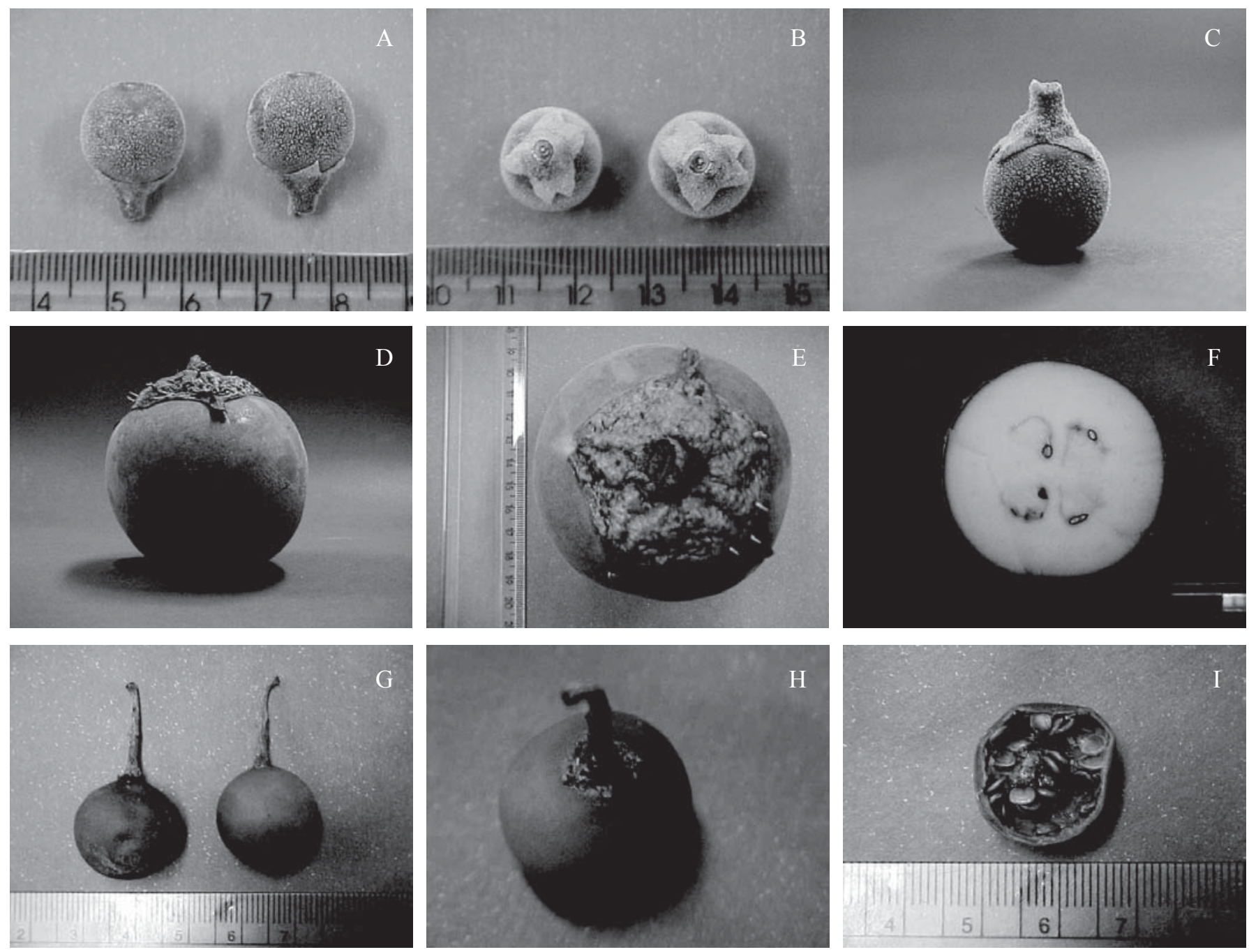

FIGURA 1. Frutos de Solanum granuloso-leprosum Dunal: vista lateral (A e C ) e vista superior (B); S. lycocarpum A.St.Hil.: vista lateral (C), vista superior (D) e corte transversal (E); S. pseudoquina A.St.Hil.: vista lateral $(\mathrm{F})$, vista superior $(\mathrm{G})$ e corte transversal $(\mathrm{H})$. 
por polpa suculenta, amarelada e aromática. Concrescido no fruto dessa espécie verifica-se parte do cálice, onde se localizam espinhos.

Frutos de $S$. pseudoquina (Figuras $1 \mathrm{G}$ a $1 \mathrm{I}$ ) apresentam 1,13 a 1,89cm de diâmetro, com endocarpo sempre verde e glabro. Meso-endocarpo constituído de polpa de coloração creme.

Morfologia das sementes. As sementes das espécies estudadas são muito semelhantes em estrutura e forma, variando somente em tamanho. Elas são campilótropas (com base em descrição feita por Corner, 1976), elipsóides ou subdiscóides, comprimidas, apresentando seção longitudinal largo-ovalada ou achatado-ovalada e seção transversal elíptica.

As sementes de $S$. granuloso-leprosum são as menores e mais leves, as de $S$. lycocarpum as maiores e mais pesadas e as de $S$. pseudoquina são de dimensões e peso intermediários (Tabela 1).

Na Figura 2, verifica-se que mais de $50 \%$ das sementes de $S$. granuloso-leprosum apresentaram de 2,15 a 2,25mm de comprimento e que cerca de $84 \%$ das sementes apresentam espessura entre 0,68 a $0,83 \mathrm{~mm}$, sendo que $44 \%$ delas mediram $0,73 \mathrm{~mm}$. A maior variação foi constatada para a largura das sementes, onde $90 \%$ delas mediram entre 1,75 a $2,15 \mathrm{~mm}$.

Para S. lycocarpum (Figura 3) a maioria das sementes apresentam em média de 6,00 a 7,00mm de comprimento e 4,58 a $5,08 \mathrm{~mm}$ de largura por 1,50 a $2,10 \mathrm{~mm}$ de espessura. São em menor porção as sementes que apresentaram dimensões inferiores ou superiores a estas.

Em S. pseudoquina $32 \%$ as sementes mediram cerca de 3,50mm de comprimento, 21\% 3,15 mm de largura e a maioria mediram de $0,88-1,13 \mathrm{~mm}$ de espessura (Figura 4). Os resultados obtidos mostram que houve uma grande variação no tamanho das sementes estudadas.

Sementes de $S$. granuloso-leprosum apresentavam-se com superfície do tegumento levemente brilhante, geralmente de coloração amarela (Figura 5A) quando viáveis e marrom quando deterioradas. Sementes de $S$. lycocarpum apresentam coloração cinza quando secas e marrom quando molhadas
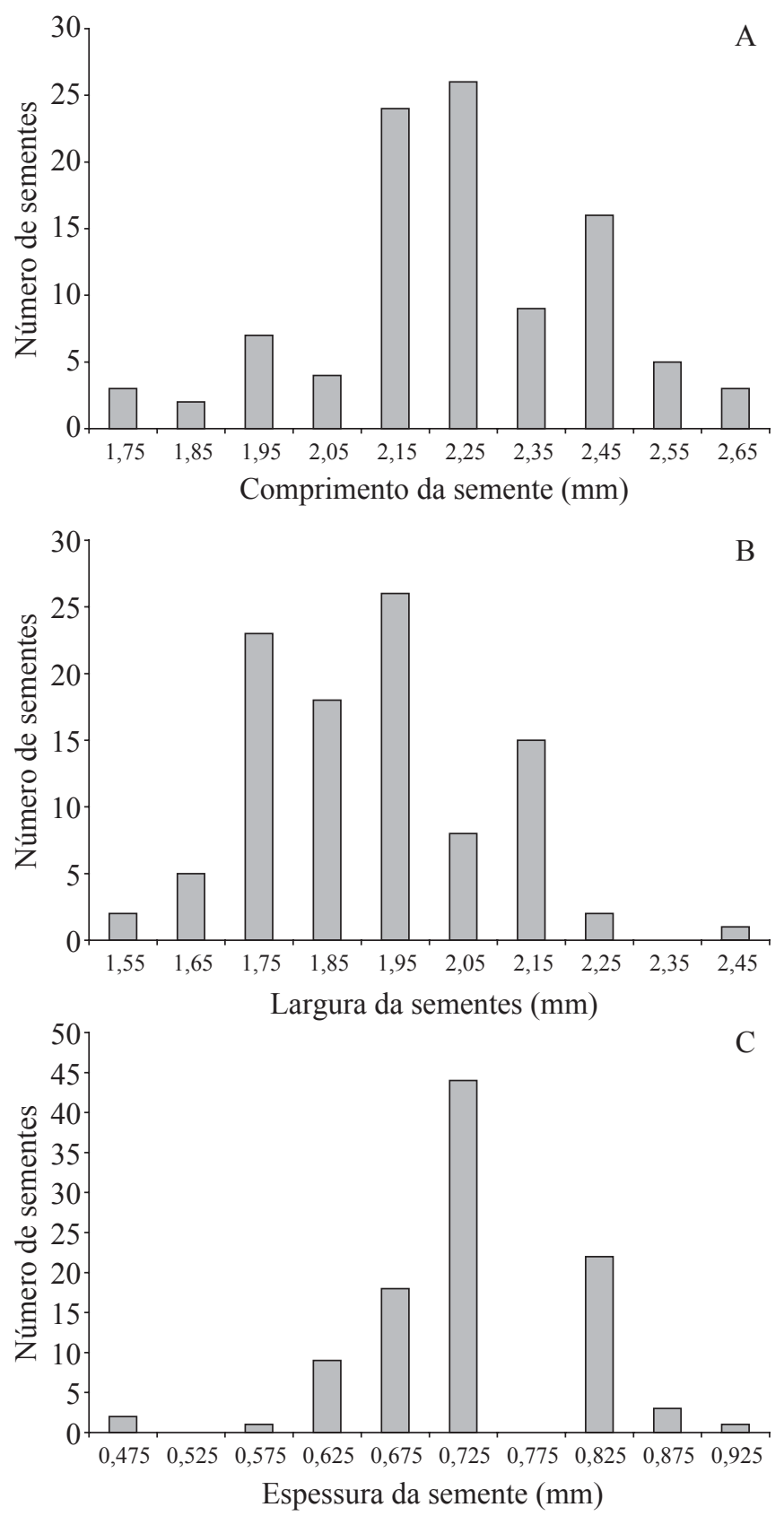

FIGURA 2. Freqüência de sementes de Solanum granulosoleprosum Dunal por categoria de comprimento (A), largura (B) e espessura (C).

TABELA 1. Médias de comprimento, largura e espessura de sementes de Solanum granuloso-leprosum, S. lycocarpum e S. pseudoquina.

\begin{tabular}{lccc}
\hline \multicolumn{1}{c}{ Espécie } & Comprimento $(\mathrm{mm})$ & Largura $(\mathrm{mm})$ & Espessura $(\mathrm{mm})$ \\
\hline S. granuloso-leprosum & 2,25 & 1,92 & 0,73 \\
S. lycocarpum & 7,04 & 5,33 & 1,71 \\
S. pseudoquina & 3,56 & 3,03 & 0,99 \\
\hline
\end{tabular}



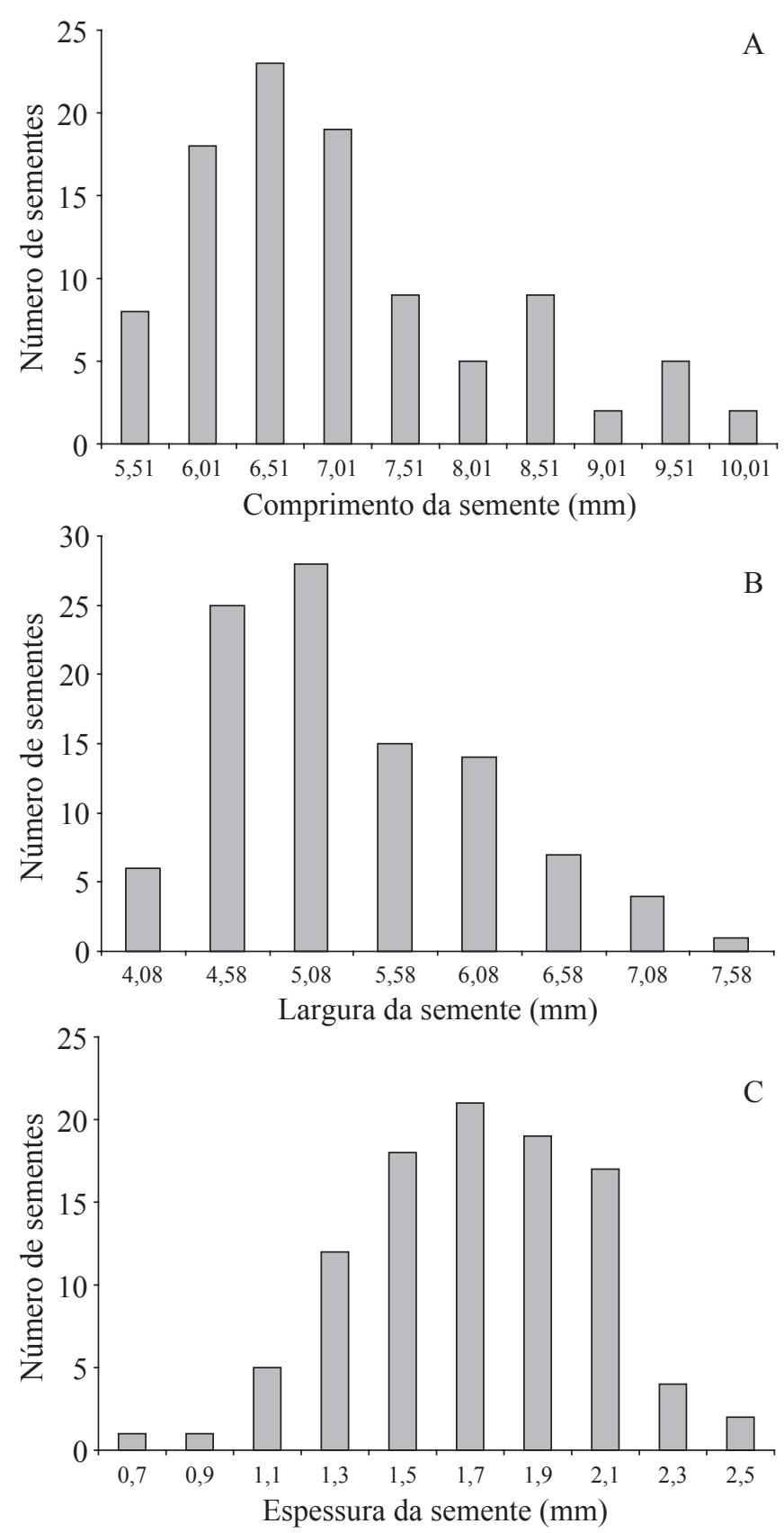

FIGURA 3. FreqüênciadesementesdeSolanumlycocarpum A.St.-Hil. por categoria de comprimento (A), largura (B) e espessura (C).

(Figura 7A). Sementes de S. pseudoquina apresentam coloração amarelo-esverdeada levemente brilhante (Figura 10A) quando viáveis, marrom quando deterioradas e amarelo-clara quando chochas; quando hidratadas, a testa torna-se transparente, permitindo visualizar o embrião no interior. Essa visualização só é possível em $S$. pseudoquina, nas outras espécies não.
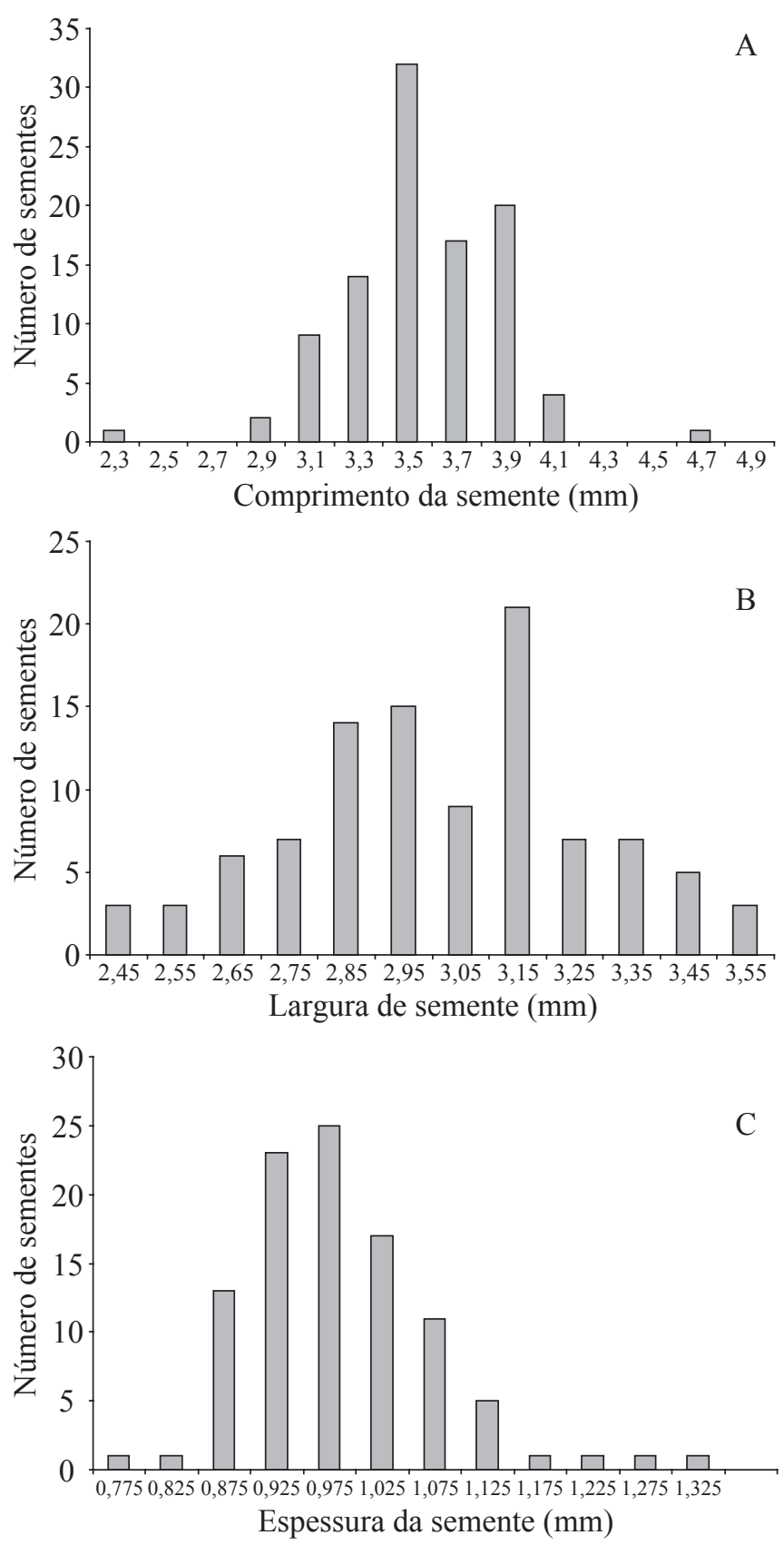

FIGURA 4. Freqüência de sementes de Solanum pseudoquina A.St.-Hil. por categoria de comprimento (A), largura (B) e espessura (C).

Topografia e morfologia externa das sementes. As sementes estudadas são estenospérmicas e não apresentam arilo. O hilo localiza-se em posição mediano-marginal, em uma depressão, sendo da mesma coloração do tegumento (Figuras 5B, 7B e 9B). A micrópila é arredondada e geralmente invisível à olho nu. 

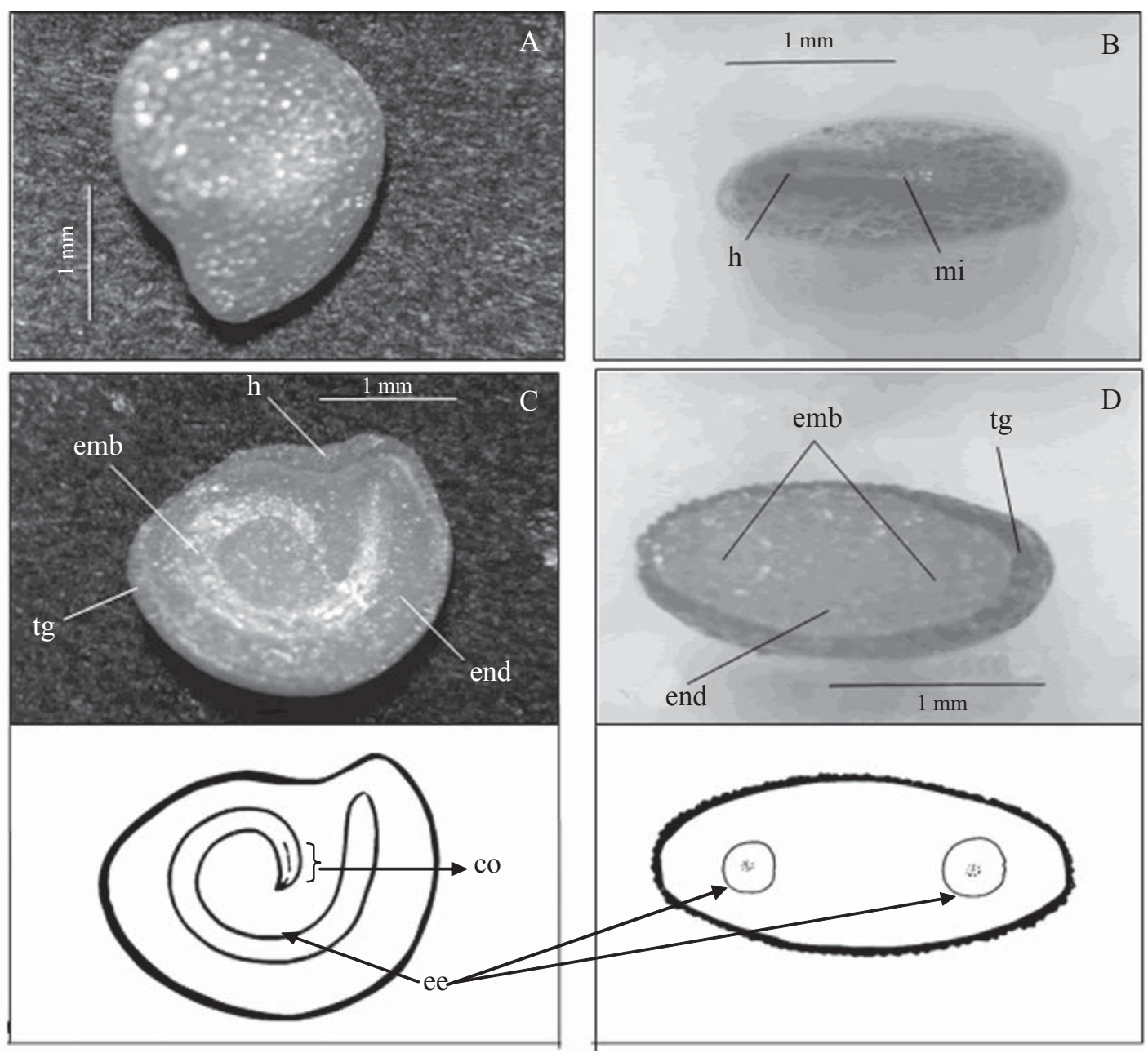

FIGURA 5. Sementes de Solanum granuloso-leprosum Dunal: A - vista externa; B - vista frontal da região do hilo; C - corte longitudinal com esquema; D - corte transversal com esquema. Legenda: $\mathbf{h}$ - hilo, mi - micrópila, tg - tegumento, end - endosperma, emb - embrião, co - cotilédones, ee - eixo embrionário.
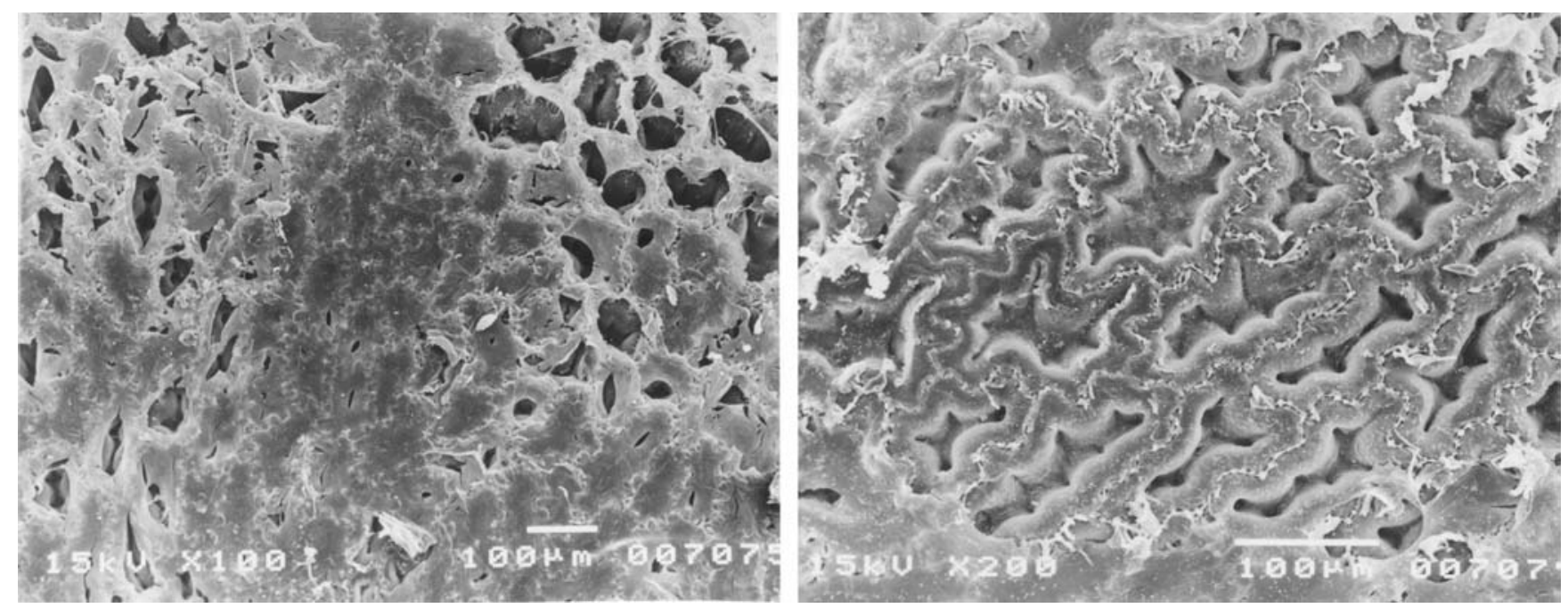

FIGURA 6. Eletromicrografia de sementes de Solanum granuloso-leprosum Dunal: vista externa do tegumento. 

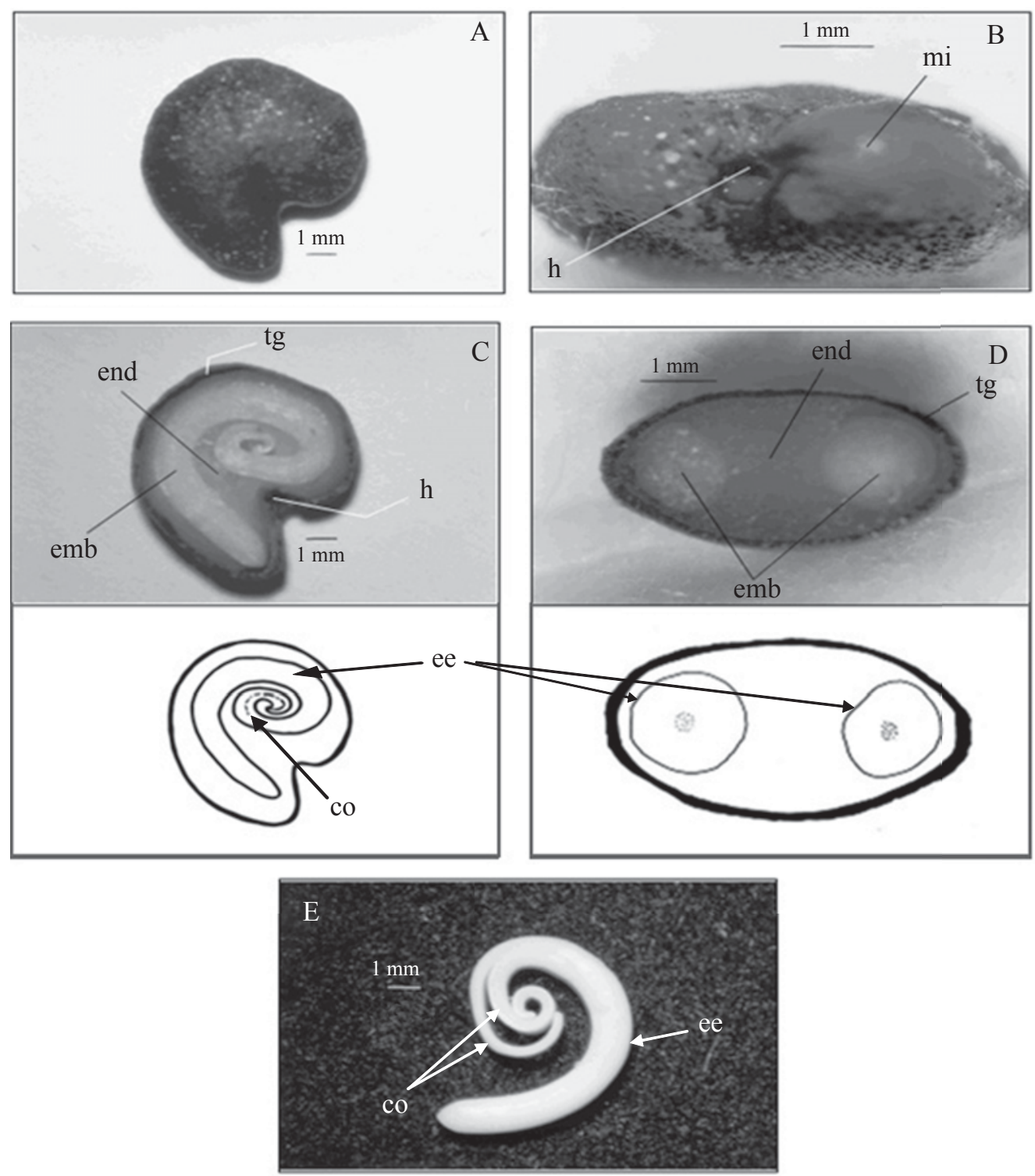

FIGURA 7. Sementes de Solanum lypocarpum A.St.-Hil.: A - vista externa; B - vista frontal da região do hilo; C corte longitudinal com esquema; D - corte transversa com esquema; $\mathbf{E}$ - embrião. Legenda: $\mathbf{h}$ - hilo, mi - micrópila, tg - tegumento, end - endosperma, emb - embrião, co - cotilédones, ee - eixo embrionário.

Genericamente, marcas laterais no tegumento da semente são denominadas de pleurogramas, de acordo com Corner (1976a), as quais, especificamente, não foram citadas pelo autor para espécies de Solanum (Corner, 1976b). Cita-se que o pleurograma é uma área especial, localizada lateralmente nas sementes, delimitadaporumalinhadefinidae, segundoosautores, a ocorrência do pleurograma é restrita às famílias Cucurbitaceae e Fabaceae, implicando em seu valor taxonômico. No presente trabalho, para S. pseudoquina observa-se uma marca lateral no tegumento de suas sementes (Figura 9A), diferenciando-a das demais espécies. A marca lateral no tegumento da semente de S. pseudoquina é causada, provavelmente, por uma quebra na construção da paliçada exotestal (Figura 11D).

As sementes estudadas são albuminosas, com endosperma abundante, periférico, carnoso-firme, semitransparente e de coloração esbranquiçada (Figuras 5C e 5D, 7C e 7D, 9C e 9D, 10A e 10B).

Para as três espécies, os embriões foram classificados, de acordo com Martin (1946), em axiais, lineares e contínuos. S. granuloso-leprosum (Figuras 5C e 5D) apresenta embrião 

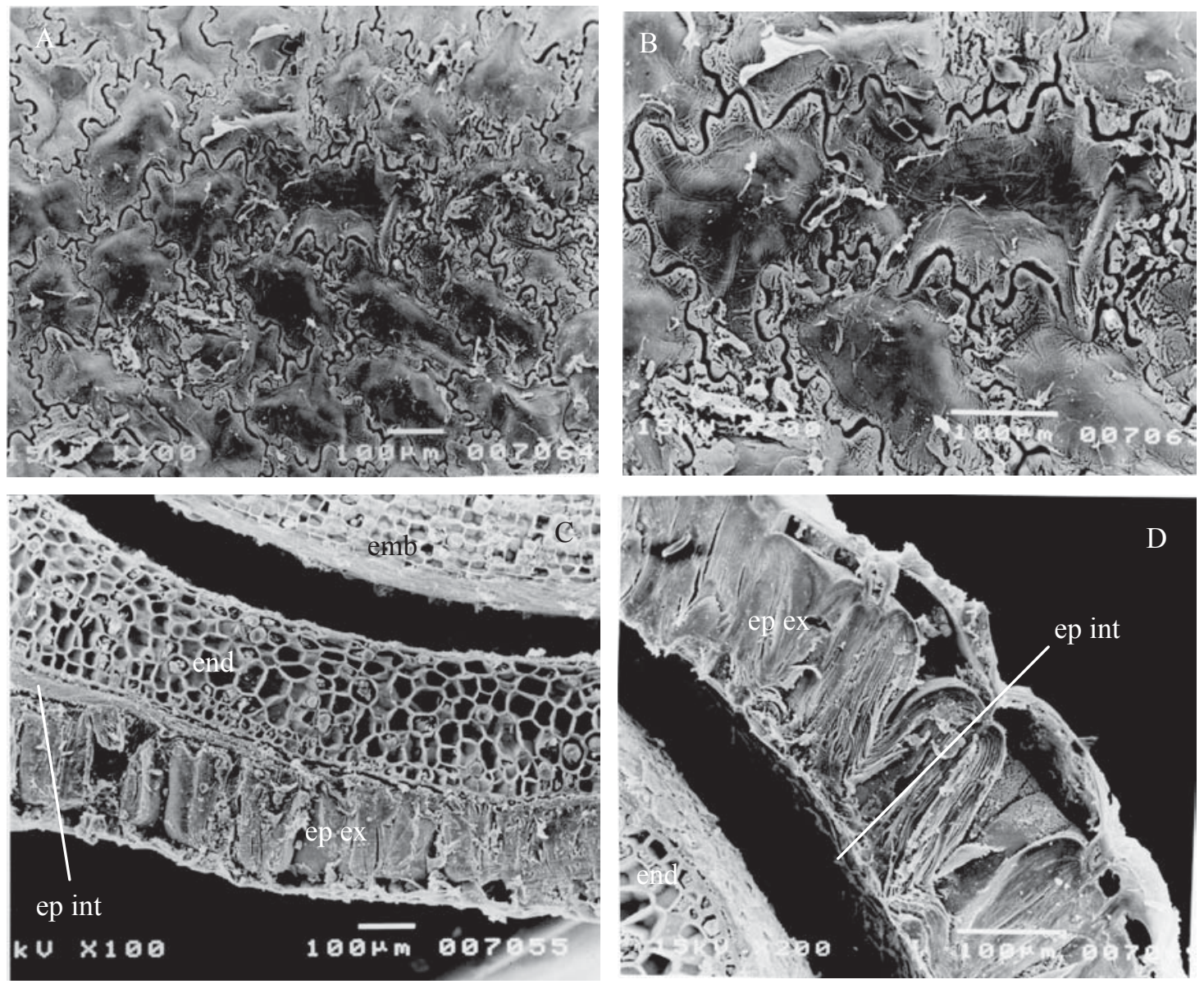

FIGURA 8. Eletromicrografia de sementes de Solanum lycocarpum A.St.-Hil.: A-B - vista externa do tegumento; C-D - corte longitudinal com destaque do tegumento. Legenda: ep ex - epiderme externa, ep int - epiderme interna, end - endosperma, emb - embrião.

curvo; já S. lycocarpum (Figuras 7C, 7D7E) e S. pseudoquina (Figuras 9C e 9D, 10C e 10D) possuem embrião circinado (cilíndrico, enrolado em espiral, com cotilédones planos com o mesmo diâmetro do eixo hipocótilo-radícula). Para as espécies em estudo, as formas descritas enquadram-se nas características descritas por Barroso et al (1999) para o gênero Solanum. Em S. granuloso-leprosum e S. lycocarpum o embrião é branco; S. pseudoquina apresenta embriões tanto de coloração branca (Figuras 9C, 10A e 10C) como de coloração escura, provavelmente devido a algum tipo de pigmento (Figuras 9D, 10B e 10D). Na literatura não foi encontrado relato de sementes que apresentam embriões viáveis com colorações escuras. Os embriões ocupam cerca de um quarto da semente.

Nos cortes transversais das sementes de S. granulosoleprosum (Figuras 5D) e de S. lycocarpum (Figuras 7D) o eixo embrionário e os cotilédones são visualizados apenas uma vez cada um deles; enquanto em S. pseudoquina (Figuras 10A e 10B) o eixo embrionário é visualizado uma vez e os cotilédones duas vezes, pelo fato de serem circinados.

Histologia do tegumento das sementes. Corner (1976) descrevendo os óvulos e as sementes de Solanaceae, indica que os óvulos são unitégmicos e as sementes deles resultantes são pequenas e albuminosas. $\mathrm{O}$ tegumento é geralmente reduzido a uma epiderme externa e outra interna, com mesófilo colapsado. A epiderme externa é formada por uma camada compacta de células, mais ou menos ondulada ou com facetas estreladas, fortemente espessadas; a epiderme interna é geralmente persistente, com uma única camada de células retangulares comprimidas. Essas características coincidem com as observadas ao microscópio eletrônico de varredura, nos cortes do tegumento das sementes das três espécies, conforme pode ser visto nas Figuras 8C e 8D, 11C e 11D. Apesar das características 

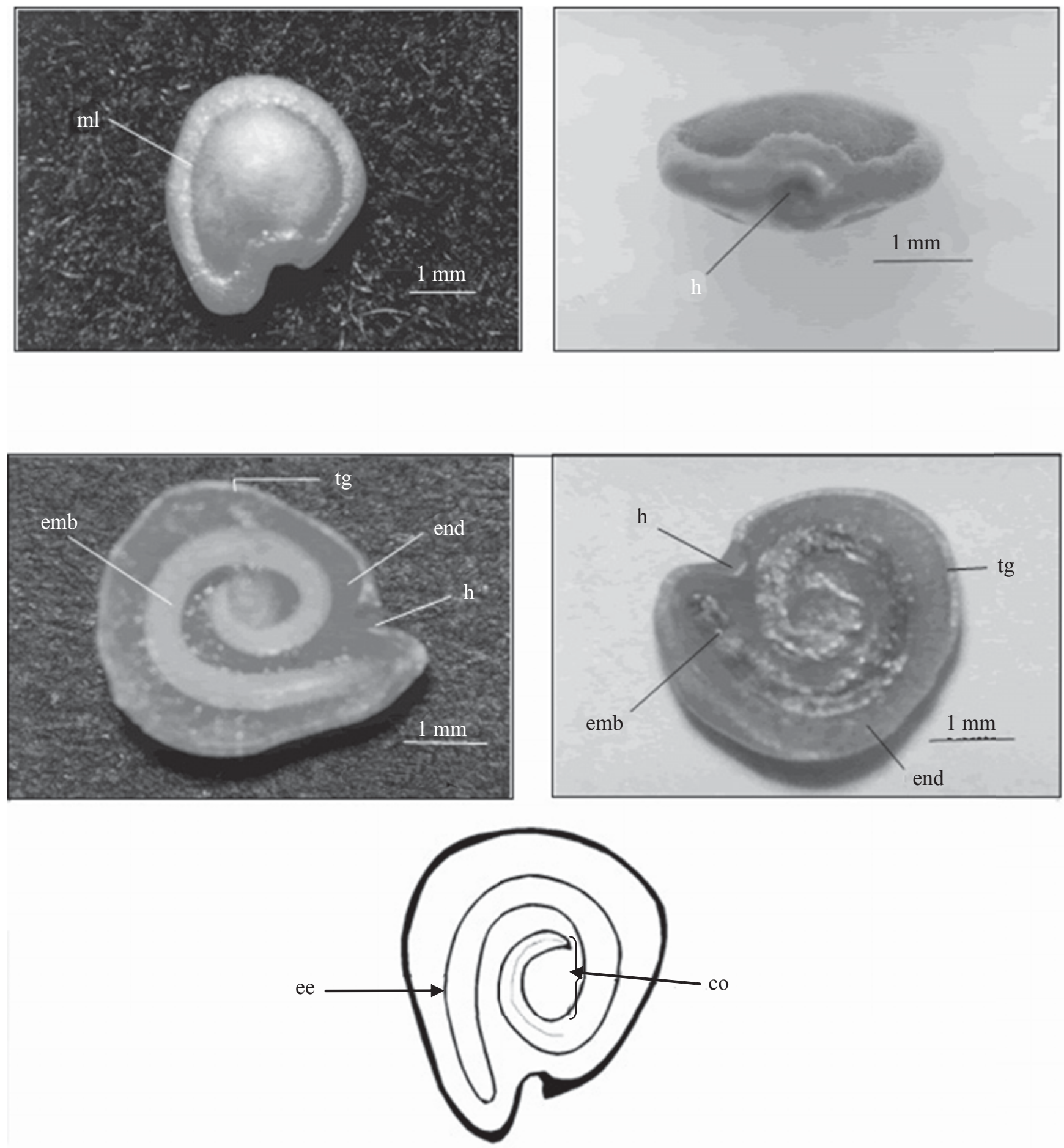

FIGURA 9. Sementes de Solanum pseudoquina A.St.-Hil.: A - vista externa; B - vista frontal da região do hilo; C corte longitudinal com embrião branco; D - corte longitudinal com embrião escuro. Os dois últimos com esquema. Legenda: $\mathrm{h}$ - hilo, tg - tegumento, end - endosperma, emb - embrião, ml - marca lateral, co cotilédones, ee - eixo embrionário. 

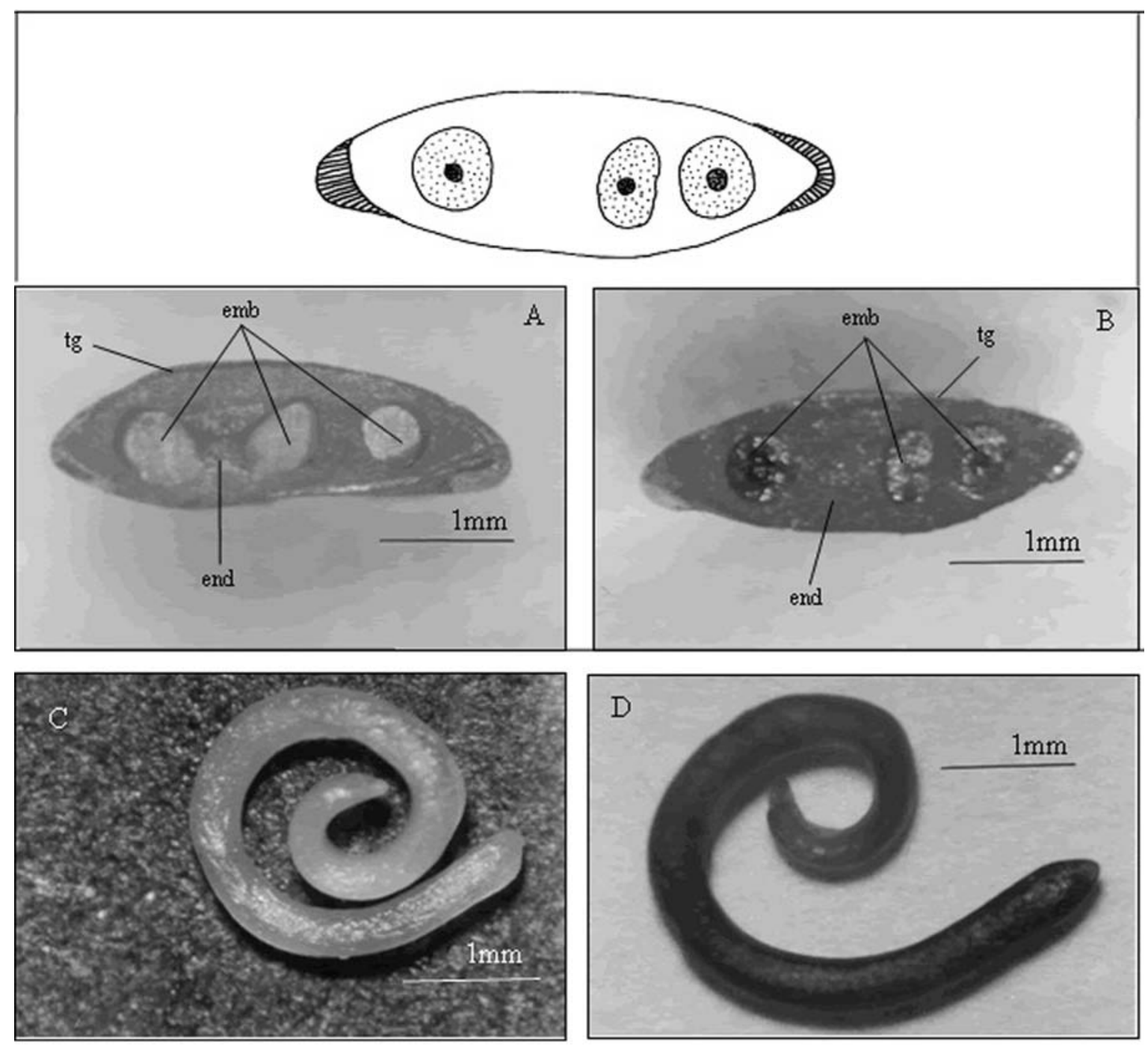

FIGURA 10. Sementes de Solanum pseudoquina: A- corte transversal do embrião branco; B- corte transversal com embrião escuro. A representação dos cortes de ambos os tipos de embriões é mostrada, esquematicamente, na figura superior, na qual as secções transversais do eixo embrionário encontram-se em pontilhado; Cembrião branco; D- embrião escuro. Legenda: tg- tegumento, end- endosperma, emb- embrião.

celulares dos tegumentos das três espécies serem semelhantes entre si, nas observações feitas nos cortes histológicos, foram verificadas nítidas separações entre elas, quando as superfícies celulares são observadas de topo. A análise da superfície das células da epiderme externa do tegumento, ao microscópio eletrônico de varredura, revelou que as três espécies apresentam parede anticlinal fortemente ondulada. S. granuloso-leprosum apresenta evidente depressão interna na parede periclinal (Figura 6), enquanto as outras duas espécies possuem paredes anticlinais niveladas (Figuras 8A e 8B, 11A e 11B). Em S. pseudoquina a parede anticlinal das células apresenta pontuações de calibre evidente, enquanto em $S$. lycocarpum não existem pontuações.
A diferenciação entre a epiderme externa do tegumento das três espécies, quando observadas ao microscópio eletrônico de varredura, é uma característica que pode auxiliar a taxonomia na identificação dessas espécies.

\section{CONCLUSÕES}

As sementes das espécies estudadas são de formato elipsóide ou subelipsóide, variando apenas em tamanho e peso. Sementes de Solanum granuloso-leprosum são menores e mais leves, as de $S$. lycocarpum são maiores e mais pesadas e as de $S$. pseudoquina são de tamanho e peso intermediários. 

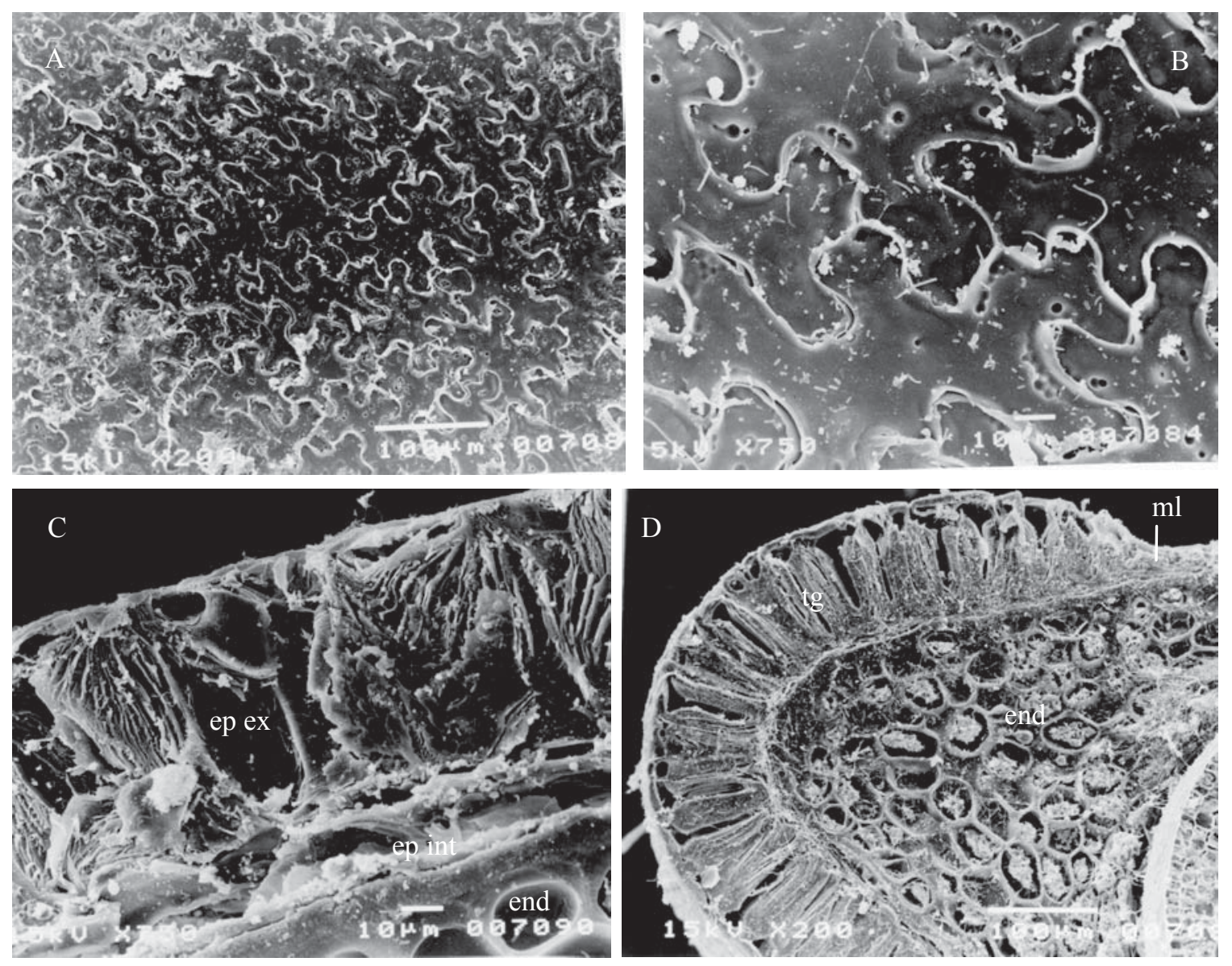

FIGURA 11. Eletromicrografia de sementes de Solanum pseudoquina: A - B- vista externa do tegumento; C- corte longitudinal do tegumento; D- corte transversal. Legenda: ep ex- epiderme externa, ep int- epiderme interna, end- endosperma, emb- embrião, ml- marca lateral.

As sementes das três espécies são albuminosas, com embrião axilar, contínuo, de formato curvado e linear, espiralado em $S$. granuloso-leprosum e circinado em $S$. lycocarpum e S. pseudoquina.

\section{REFERÊNCIAS}

ALMEIDA, S.P.; PROENÇA, C.E.B.; SANO, S.M.; RIBEIRO, J.F. Cerrado: espécies vegetais úteis. Planaltina: EMBRAPA-CPAC, 1998. p.332-335.

BARROSO, G.M.; MORIM, M.P.; PEIXOTO, A.L.; ICHASO, C.L.F. Frutos e sementes: morfologia aplicada a sistemática de dicotiledôneas. Viçosa: UFV, 1999. 443p.

CASTELLANI, E.D. Caracterização e ecofisiologia de sementes de três espécies arbóreas do gênero Solanum $\mathbf{L}$. Jaboticabal, 2003. 200f. Tese (Doutorado em Agronomia)
- Universidade Estadual Paulista, Faculdade de Ciências Agrárias e Veterinária, Jaboticabal, 2003.

CORNER, E.J.H. The seeds of dicotyledons. Cambridge: University Press, 1976a. v.1, p.7.

CORNER, E.J.H. The seeds of dicotyledons. Cambridge: University Press, 1976b. v.1, p.254-255.

DAMIÃO-FILHO, C.F. Morfologia vegetal. Jaboticabal: FUNEP, 1993. 243p.

DAVIDE, A.C.; FARIA, J.M.R.; BOTELHO, S.A. Propagação de espécies florestais. Belo Horizonte: CEMIG, 1995. 41p.

DE-PAULA, O.C.; OLIVEIRA, D.M.T. Pleurogramas múltiplos em sementes de Caesalpioideae (Fabaceae). In: CONGRESSO DA SOCIEDADE BOTÂNICA DE SÃO PAULO, XVI, 2006, Piracicaba. Resumo... Piracicaba 
Disponível em: <http://www.biota.org.br/publi/banco/ docs/31177_1159977343.pdf $>$. Acessado em: 22/05/2006.

GROTH, D.; LIBERAL, O.H.T. Catálogo de identificação de sementes. Campinas: Fundação Cargill, 1988. n.1, 183p.

KAGEYAMA, P.Y.; VIANA, V.M. Tecnologia de sementes e grupos ecológicos de espécies arbóreas tropicais. In: SIMPÓSIO BRASILEIRO SOBRE TECNOLOGIA DE SEMENTES FLORESTAIS, 2, 1989, Atibaia. Anais... São Paulo: Instituto Florestal, 1991. p.197-215.

KISSMANN, K.G.; GROTH, D. Plantas infestantes e nocivas. 1.ed. São Paulo: BASF, 1995. t.3, p.541-547.

KISSMANN, K.G.; GROTH, D. Plantas infestantes e nocivas. 2.ed. São Paulo. BASF, 2000. t.3, p.569-571 e p.577-580.

KUNIYOSHI, Y.S. Morfologia da semente e da germinação de 25 espécies arbóreas de uma floresta com araucária. Curitiba, 1983. 233f. Dissertação (Mestrado em Engenharia Florestal) - Universidade Federal do Paraná, Curitiba, 1983.

LORENZI, R. Árvores brasileiras: manual de identificação e cultivo de plantas arbóreas nativas do Brasil. Nova Odessa: Plantarum, 1998. v.2, p.326-327

MARTIN, A.C. The comparative internal morphology of seeds. The American Midland Naturalist, Indiana, v.36, n.3, p.513-660, 1946.

PIÑA-RODRIGUES, F.C.M.; AGUIAR, I.B. Maturação e dispersão de sementes. In: AGUIAR, I.B.; PINÃRODRIGUES, F.C.M.; FIGLIOLIA, M.B. (Coord.) Sementes florestais tropicais. Brasília: ABRATES, 1993. p.215-274.

PINHEIRO, F.; RIBEIRO, J.F. Síndromes de dispersão de sementes em mata de galeria no Distrito Federal. In:
RIBEIRO, J.F.; FONSECA, C.E.L.; SOUSA-SILVA, J.C. Cerrado: caracterização e recuperação de mata de galeria. Planaltina: EMBRAPA Cerrados, 2001. p.335-375.

PRADO, N.J.S.; FONSECA, E.M.B.; ROLIM, A.A.B. Viveiro florestal: implantação e técnica de produção de mudas. Belo Horizonte: CEMIG, 1996. 25p

PRADO, N.J.S.; RESENDE, A.P.S.; FONSECA, E.M.B. Experiência da Cemig na implantação de mata ciliar. In: SIMPÓSIO MATA CILIAR: CIÊNCIA E TECNOLOGIA, 1999, Belo Horizonte. Palestras... Lavras: UFLA/FAEPE/ CEMIG, 1999. p.224-234.

ROE, K.E. A revision of Solanum section Brevantherum (Solanaceae). Brittonia, New York, v.24, n.3, p.239-278, 1972.

SANTOS, J.M. Microscopia eletrônica de varredura aplicada às ciências biológicas. Jaboticabal: FUNEP, 1992. $27 \mathrm{p}$.

SILVA, A. Técnicas de secagem, extração e beneficiamento de sementes. In: SILVA, A.; PIÑA-RODRIGUES, F.C.M.; FIGLIOLIA, M.B. Manual técnico de sementes florestais. São Paulo: Instituto Florestal, 1995. p.21-32. (IF Série Registros, 14).

SILVA, A.; FIGLIOLIA, M.B.; AGUIAR, I.B. Secagem, extração e beneficiamento de sementes. In: AGUIAR, I.B.; PIÑA-RODRIGUES, F.C.M.; FIGLIOLIA, M.B. (Coord.). Sementes florestais tropicais. Brasília: ABRATES, 1993. p.303-332.

TRAPE, M.Z.; OLIVEIRA, C. Ficha de espécies nativas. Florestar Estatístico, São Paulo, v.2, n.6, p.71-77, 1995.

VAN DER PIJL, L. Principles of dispersal in higher plants. 3.ed. Berlim: Springer-Verlag, 1982. 214p. 